
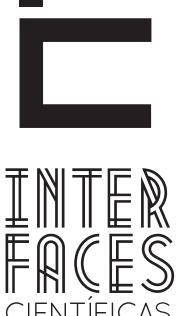

CIENTÍFICAS

HUMANASE SOCIAIS

ISSN IMPRESSO 2316-3348

E-ISSN 2316-3801

DOI - 10.17564/2316-3801.2018v6n3p145-154

\title{
REPRESENTAÇ̃̃O SOCIAL DE COMUNIDADE E ELEMENTOS DE AUTOIDENTIDADE PARA MORADORAS DE CONJUNTO HABITACIONAL POPULAR
}

\author{
SOCIAL REPRESENTATION OF COMMUNITY AND ELEMENTS OF SELF-IDENTITY FOR PEOPLE OF POPULAR HOUSING SET \\ REPRESENTACIÓN SOCIAL DE COMUNIDAD Y ELEMENTOS DE AUTOIDENTIDAD PARA MORADORAS DE \\ CONJUNTO HABITACIONAL POPULAR
}

\author{
Elza Francisca Corrêa-Cunha ${ }^{1}$ \\ Stella Rabello Kappler ${ }^{3}$ \\ Isabela dos Santos ${ }^{5}$
}

\author{
Neilson Santos Meneses ${ }^{2}$ \\ Carmelita Rikely Santos ${ }^{4}$
}

\section{RESUMO}

Este trabalho analisa as categorias representação social de comunidade e elementos de autoidentidade que emergiram de um estudo com vinte mulheres moradoras de um conjunto habitacional popular. Aplicou-se um roteiro semiestruturado de entrevista em uma amostra selecionada por conveniência. Os dados sociodemográficos foram tratados pelo programa SPSS-20 e as informações subjetivas interpretadas pela Análise do Discurso. $\mathrm{Na}$ caracterização sociodemográfica apurou-se que a idade média das participantes foi de 32 anos; a renda média familiar foi 0,8 salários mínimos. 0 tempo médio de anos de estudos da amostra foi de 7,5; a média de filhos residentes com a mãe foi 1,8 e o tempo médio de moradia na comunidade foi 9,7 anos. Quanto às categorias de análise, observou-se que na representação de comunidade, foram apontadas: união, busca comum, violência e falta de estrutura. Quanto aos elementos identitários, a maioria das mulheres reportou-se aos papéis sociais caracterizados pelo desempenho nas tarefas domésticas e sobre o próprio corpo, tendo sido encontrado ainda papéis de mãe, filha e estudante. Os dados obtidos sobre autoidentidade e representação de comunidade corroboraram os achados da literatura especializada nas referidas áreas.

\section{PALAVRAS-CHAVE}

Representação de Comunidade. Papéis Sociais. Autoidentidade Feminina. Trabalho Doméstico. Corpo Feminino. 


\section{ABSTRACT}

This paper analyzes the categories social representation of community and elements of self-identity that emerged from a study with twenty women residents of low income community. A semistructured interview script was applied on a sample selected for convenience. Sociodemographic data were processed by the SPSS-20 program and the subjective information interpreted by Discourse Analysis. The average age of participants was 32 years old; the average family income was 0.8 , below a minimum wage. The average time of studies was 7.5 , the number of resident children with a mother ranged from one to two (average of 1.8) and the average length of community living was 9.7 years. In the community representation, we found:

\section{RESUMEN}

Este trabajo analiza las variables de representación social de comunidad y elementos de autoidentidad que surgieron de un estudio con veinte mujeres moradoras de un conjunto habitacional popular. Se aplicó un guion semiestructurado de entrevista en una muestra seleccionada por conveniencia. Los datos sociodemográficos fueron procesados con el programa SPSS-20 y la información subjetiva interpretada mediante el método de Análisis del Discurso. La edad media de las participantes fue 32 años y el promedio de la renta familiar 0,8 , por debajo de un salario mínimo brasileño. El tiempo promedio de estudios fue 7,5; el número de hijos residentes con madre varió entre uno y dos (promedio de 1,8) y el tiempo promedio de vivienda en la comunidad fue de 9,7 años. En la va- union, common search, violence and lack of structure. As for the identity elements, most of the women reported to the social roles characterized by the performance in the domestic tasks and on the body, it has been founded functions of mother, daughter and student. The data obtained on self-identity and community corroborated the findings of the specialized literature in these areas

\section{KEYWORDS}

Representation of Community. Social Roles. Feminine Self-Identity, Housework. Female Body.

riable de representación de comunidad, se encontró: unión, búsqueda común, violencia y falta de estructura. En cuanto a los elementos identitarios, la mayoría de las mujeres se identificaron con los roles sociales caracterizados por el desempeño en tareas domésticas y sobre el cuerpo, y se encontraron también roles de madre, hija y estudiante. Los datos obtenidos sobre autoidentidad y comunidad corroboraron los hallazgos de la literatura especializada en dichas áreas.

\section{PALABRAS CLAVE}

representación de comunidad, roles sociales, autodefensa femenina, trabajo doméstico, cuerpo femenino. 


\section{INTRODUÇ̃̃O}

Este artigo refere-se a um conjunto de dados oriundos de projetos de pesquisa e de extensão universitária, realizados em uma comunidade de baixa renda. Entre uma série de atividades investigativas, foram estudados os principais papéis sociais femininos desempenhados pelas moradoras do referido local a partir das suas próprias falas. Das informações obtidas emergiram algumas categorias, entre as quais este trabalho se propõe a examinar duas, uma referente à representação social de comunidade e a outra relacionada aos elementos de autoidentidade feminina.

Os estudos de representação social têm se constituído uma importante área de pesquisas em Psicologia Social e estão relacionados com um amplo campo de estudos psicossociais. Segundo Sá (2015, p. 183) “o termo designa tanto um conjunto de fenômenos quanto o conceito que os engloba e a teoria construída para explicá-los”. Moscovici (apud SÁ, 2015, p. 187), precursor da teoria das representações sociais, considerando uma psicossociologia do conhecimento, afirmou que tais representações seriam reduzidas a "uma modalidade específica de conhecimento que tem por função a elaboração de comportamentos e a comunicação entre indivíduos, no quadro da vida cotidiana".

Entre uma miríade de questões que são representadas, a partir das ideias que os sujeitos têm dos fenômenos, o mencionado autor acredita que essas explicações do cotidiano, não são apenas opiniões ou atitudes em relação aos objetos sociais envolvidos. Mas, que nos comentários emitidos, estão envolvidas combinações de diferentes escopos e objetos, que correspondem a "uma lógica própria, com estrutura globalizante de implicações, para qual contribuem informações e julgamentos valorativos colhidos nas mais variadas fontes institucionais e em experiências pessoais e grupais" (MOSCOVICI apud SÁ, 2015, p. 189). Nesta perspectiva, os conceitos e as afirmações são "verdadeiras teorias do senso comum, ciências coletivas suis generis, pelas quais se procede à interpretação e mesmo à construção das realidades sociais" (MOSCOVICI apud SÁ, 2015, p. 48).
Em nossa sociedade, o trabalho doméstico se caracteriza como predominantemente feminino. Tal afirmação pode ser observada pelo relatório sobre o perfil dos trabalhadores domésticos nas seis regiões metropolitanas investigadas pelo IBGE, que em 2006 apontou na execução dos trabalhos domésticos, percentuais de $5,7 \%$ de homens contra $94,3 \%$ de mulheres. Alguns autores acreditam que essa diferença, referente à construção histórica dos papéis sociais, ainda é um estigma carregado por elementos preconceituosos, tendo em vista que tal construção se baseia no argumento de que as empregadas domésticas desempenham tais tarefas por possuírem qualificações destinadas e próprias à mulher (TOLEDO, 2008).

Atualmente, compreende-se por trabalho doméstico a realização, no domicílio de residência, de tarefas que não se enquadram no conceito de trabalho: arrumar ou limpar toda ou parte da moradia; cozinhar ou preparar alimentos, passar e lavar roupa ou louça, tarefas executadas para si ou para outro(s) morador(es). (IBGE, 2015). A este respeito, Pena (1981, p. 73), ressalta que o trabalho doméstico, cria valores de uso e garante a reprodução social de trabalhadores e familiares, constituindo-se a essência da opressão feminina. Desta forma, o casamento, torna-se o mecanismo social de legitimação por se apropriar da condição de donas de casa, responsáveis pela reprodução, principalmente por meio de serviços prestados gratuitamente.

A literatura científica sobre autoidentidade afirma que o seu desenvolvimento implica em um processo dialético entre um indivíduo e a sociedade. Berger e Luckmann (1976) alegam que esse processo é o resultado das diversas interações socioambientais com o indivíduo. Neste sentido, a identidade social de cada pessoa se caracteriza pelo conjunto das suas vinculações sociais.

A autoidentidade, segundo Giddens (2002, p. 39) desenvolve-se dentro do quadro geral da constituição psicológica do indivíduo, em que "Ser humano é saber quase sempre, em termos de uma descrição ou outra, tanto o que se está fazendo como porque se está fazendo". Esta consciência reflexiva permeia toda ação humana e é a condição específica da refle- 
xividade institucional maciçamente desenvolvida, o que, segundo o autor, é um componente intrínseco da modernidade. Nesta perspectiva, todos os homens monitoram continuamente as circunstâncias de suas atividades como parte do fazer o que fazem e esse monitoramento sempre tem características discursivas. Isto significa que ao ser interpelado, o agente faz interpretações discursivas da natureza e das razões do seu comportamento.

Castells (2002, p. 22) faz uma distinção entre identidade e papéis sociais. Ele entende por identidade "o processo de construção de significado com base em um atributo cultural, ou ainda um conjunto de atributos culturais inter-relacionados, o(s) qual(is) prevalece $(m)$ sobre outras fontes de significado". Este seria originado e construído pelos sujeitos por meio do processo de individuação. No caso dessas identidades serem formadas a partir de instituições dominantes, o processo se dá a partir da internalização das regras e significados institucionais. Para o autor, existem múltiplas identidades, o que, em seu entendimento, seria fonte de tensão e contradição para o sujeito, na sua autorrepresentação e na sua ação social.

Por outro lado, Castells (2002), afirma que os papéis sociais são determinados por organizações sociais, como nos papéis de militante político, trabalhador, mãe, vizinho, religioso, entre uma diversidade de outros possíveis de serem desempenhados por um/a único/a ator/a. Esse pesquisador acrescenta que a importância dos papéis sociais na influência do comportamento depende das negociações entre o sujeito e as instituições. Enquanto tais papéis organizam funções, a identidade organiza significados e é marcada pela maior fonte de significados devido aos processos de autoconstrução e individuação realizadas pelo sujeito. O significado organiza-se, especialmente, em torno de uma identidade primária, aquela que estrutura as demais e que se mantém ao longo do tempo e do espaço.

Para Bauman (2001) não há afirmação que não seja uma autoafirmação, nem identidade que não seja construída. Ao analisar possíveis razões da volatilidade das identidades, este estudioso considera que a forma de estar junto é a única e compatível com a modernidade, afirmada por ele como "líquida”, tendo em vista que:

\begin{abstract}
As crenças, valores e estilos foram "privatizados" descontextualizados ou "desacomodados", com lugares de reacomodação que mais lembram quartos de motel que um lar próprio e permanente -, as identidades não podem parecer frágeis e temporárias, e despidas de todas as defesas exceto a habilidade e determinação dos agentes que se aferram a elas e as protegem da erosão. A volatilidade das identidades, por assim dizer, encara os habitantes da modernidade líquida. (BAUMAN, 2001, p. 204).
\end{abstract}

O termo comunidade é conceituado por teóricos como Tönnies (1942 apud BRANCALEONE, 2008) em oposição à sociedade, sendo o primeiro termo considerado como tradicional e caracterizado pelas relações pessoais e de afetividade, comprometimento moral - de moral e valores compartilhados pelo grupo e de coesão social. Assim, a comunidade é voltada para seu interior, onde predominam os hábitos e costumes e a cooperação, é um tipo de organização que caracteriza grupos, como a família, aldeias e pequenos grupos urbanos. Mocellim, (2011), por outro lado, afirma que a sociedade é uma organização racional, marcada pelo individualismo, impessoalidade das relações, que significa um menor compartilhamento de valores e baixo grau de intimidade.

Tönnies (1942 apud BRANCALEONE, 2008) formulou as teorias de sociedade e de comunidade, tendo suas ideias absorvido os pressupostos aristotélicos do homem ser animal gregário. Assim, as ações oriundas das vontades e suas forças, quando no sentido de conservação (ou de destruição) formariam uma união. Esta, quando configurada predominantemente pela vontade natural, seria caracterizada como comunidade (gemeinschaft). Segundo o autor, na comunidade os homens permanecem unidos apesar das separações e na sociedade separados apesar de todas as uniões.

$\mathrm{Na}$ sociedade, a vontade é considerada como subjetiva, moralmente autônoma, independente e autossuficiente, estando para si em um estado permanente de tensão com as demais, sendo as outras 
vontades, na maioria das vezes, consideradas atos de hostilidade. Em seus trabalhos, encontra-se a classificação das relações comunitárias: as autoritárias, com base na força da autoridade, representada pelo modelo entre pais e filhos. As de companheirismo, como no relacionamento entre irmãos e as relações mistas, que combinariam as duas formas, típico da convivência entre cônjuges (TÖNNIES, 1942 apud BRANCALEONE, 2008).

\section{MÉTODO}

A investigação que originou o artigo incluiu 20 mulheres, selecionadas por conveniência, todas eram moradoras em um conjunto habitacional popular, situado na cidade de Aracaju. Adotou-se como critério para composição da amostra ser moradora da referida localidade por um período maior que dois anos. Tais critérios permitiriam às mulheres falarem sobre os papéis sociais que desempenham e sobre a comunidade onde moram.

A coleta de dados foi realizada no período entre janeiro e fevereiro de 2017, nas residências, na praça e na rua principal da comunidade alvo do projeto. As mulheres eram abordadas e solicitadas a participarem da pesquisa. As pesquisadoras explicavam, para as possíveis participantes, os objetivos da investigação e os princípios do Termo de Consentimento Livre e Esclarecido (TCLE) e mediante a resposta positiva, elas assinavam o referido documento. Ressalta-se que o projeto ao qual esta investigação está ligada foi aprovado pelo Comitê de Ética para pesquisa com humanos sob o número Certificado de Apresentação para Apreciação Ética (CAAE): 67487917.1.0000.5546.

0 roteiro de entrevista aplicado, em sua primeira parte, investigou características sociodemográficas da amostra. A segunda parte, composta por cinco blocos de questões, indagou acerca do desempenho de papéis femininos (pessoais e coletivos), opiniões sobre o próprio corpo, trabalhos doméstico e remunerado, bem como significado e características relevantes da comunidade.
As respostas às questões objetivas foram assinaladas pelas entrevistadoras na presença da entrevistada e as respostas subjetivas foram gravadas em áudio. 0 conteúdo obtido por meio das gravações foi transcrito na íntegra para posterior análise.

\section{RESULTADOS}

Os resultados configuraram uma investigação quantitativa e qualitativa. Neste sentido, os dados sociodemográficos foram tratados a partir do programa SPSS-20 e as informações referentes à entrevista interpretadas pela Análise do Discurso, segundo Rocha-Coutinho (1990).

\subsection{CARACTERIZAÇÃO SOCIODEMOGRÁFICA DA AMOSTRA}

O levantamento dos dados mostrou que a idade média das mulheres foi de 32 anos e a média da renda familiar foi 0,8, caracterizando-se abaixo de um salário mínimo. Trabalhavam dentro e fora do próprio lar 10\% das entrevistadas e $90 \%$ se declararam donas de casa. 0 tempo médio de anos de estudo foi de 7,5; o número de filhos residentes com mãe variou entre um e dois $(M=1,8)$ e 0 tempo médio de moradia na comunidade foi 9,7 anos.

\subsection{DESCRIÇ̃̃O DOS DADOS QUALITATIVOS}

Das informações oriundas das entrevistas surgiram algumas categorias, das quais, neste trabalho, analisamos: Representação Social de Comunidade e Elementos da Autoidentidade, descritas a seguir, com os respectivos extratos dos depoimentos. Ressalta-se que as participantes foram identificadas pelo número do roteiro de entrevista, o qual obedeceu à ordem da coleta de dados.

Representação Social de Comunidade - Esta categoria se refere às opiniões das mulheres investigadas, a respeito de comunidade. Em seus depoimentos, elas expressaram tanto aspectos positivos como negativos, como nos exemplos apresentados a seguir: 
Comunidade é um grupo de pessoas envolvidas pra alguma coisa (E. 2).

Pra mim, comunidade, acho que... as pessoas serem unidas. As pessoas são mais unidas aqui, né? Todo mundo fala com todo mundo... Mas também, tem muita desunião, gostam de tá falando da vida das outras pessoas (E.10)

A comunidade também não deixa de ser nossa família né? Porque quando a gente convive com o vizinho, a gente dorme, acorda e olha o vizinho. Eu gosto de morar aqui. Independente, se a gente for analisar a [nome do bairro] é dividida em duas partes, a parte de quem mora perto da praia, que é a parte de quem tem dinheiro, e a parte de quem mora perto da maré, que é quem não tem dinheiro e que todo mundo tem medo. Mas, eu acho calmo, eu não acho tão perigoso como as pessoas falam... Reconheço que falta uma estrutura, mas isso aqui não é só na comunidade (E.5).

Eu queria que o povo parasse de se matar, é muita falta de segurança (E. 3).

Ao apontarem conflito e violência, as falas das participantes reforçam a definição de comunidade expressa por Burke (2002), de ser um espaço de atitudes conflituosas que necessitam ser construídos e reconstruídos constantemente. Neste sentido, Campos (2004, p. 34-35), afirma: "A sociedade para Marx (1983) não é harmoniosa, mas conflitiva, sendo que o harmonioso e o conflito não são determinados pela presença de valores comunitários, mas por problemas nas relações de produção".

No que se referem aos conflitos apontados pelas participantes, Leandro (2008) concorda que a diversidade das tecnologias de comunicação dentro da comunidade, promove uma maior interação entre o interior e exterior que dificulta a unidade e a homogeneidade do grupo e gera a diversificação dos valores, da moralidade e dos hábitos adotados por seus membros.

As características opostas apresentadas pela entrevistada $\mathrm{n}^{0} 5$, entre os dois diferentes grupos socioeconômicos moradores no bairro, têm reflexo nas análises de Bauman (2001). Este acredita que como todo grupo social, a comunidade é definida em oposição a outros grupos, o que gera o sentimento de pertencimento de seus membros. A diferenciação espacial e de classe são importantes componentes para a caracterização dos pequenos grupos urbanos, principalmente periféricos, como grupos comunitários, o que contribui, sobretudo, para a construção de uma identidade.

A este respeito, Bauman (2001, p. 205-206) afirma que tendo em vista que as armas de defesa são diferencialmente distribuídas na população, os grupos mais fracos, mal armados se unem coletivamente para compensarem sua impotência. 0 autor comenta a semelhança entre os enclaves mais bem guardados com os guetos étnicos pobres e ressalta a diferença entre eles: os primeiros têm livre escolha e seus "guardadores" portam armas legais.

Elementos da Autoidentidade - Esta categoria refere-se aos depoimentos das entrevistadas sobre a perspectiva que têm acerca de si. Elas falaram sobre o próprio corpo, o que mais gostam de fazer (referindo-se prioritariamente em cuidar da família e realizar tarefas domésticas). Assinala-se, que os relatos sobre o corpo e os afazeres domésticos tiveram as mais altas incidências, podendo-se dizer que, os últimos foram quase unânimes. Ao ser interpelada a respeito de “quem é você?", a entrevistada no 5, respondeu:

Eu acho que ninguém sabe na verdade quem é ninguém e nem nós mesmos. Eu acho que hoje em dia eu sou uma mulher que ainda procura estabilidade financeira, vou conseguir. Eu ainda sou estudante, agora estou na área de turismo. Sou filha, sou mãe e sou noiva (E. 5).

Pode-se constatar no nível micro social que os discursos pessoais reproduzem os argumentos teóricos explícitos na literatura científica. Nesse sentido, observa-se a diversidade de papéis vivenciados e desempenhados pelas participantes nas mais diversas conjunturas sociais pelas quais elas transitam. Segundo Silva (2000), as pessoas vivem no centro de um imenso número de diferentes instituições. Estas, para Bourdieu (2003, p. 24), seriam os "campos sociais", 
os quais envolvem relações de força e dominação. As relações entre indivíduo e sociedade são permeadas “pela distribuição do capital” e entre eles, podem-se encontrar as famílias, grupos de colegas e de trabatho, as instituições políticas e educacionais.

O supracitado autor afirma que exercemos, nos diversos campos sociais, variados graus de escolha e autonomia, sendo que cada um tem um determinado contexto material, um espaço, um lugar e um conjunto de recursos simbólicos. Na casa, por exemplo, exerce-se a identidade familiar e assiste-se a representação que a mídia produz determinadas identidades a partir de informações diversas. Embora vendo-nos como determinada pessoa, nos diversos papéis encontrados e experienciados, percebemos nossa posição diferenciada a partir do momento, do lugar e dos diferentes papéis sociais que nos envolvemos, nos diferentes significados sociais:

Diferentes contextos sociais fazem com que nos envolvamos em diferentes significados sociais. Em todas as situações, podemos nos sentir, literalmente, como sendo a mesma pessoa, mas nós somos, na verdade, diferentemente posicionados pelas diferentes expectativas e restrições sociais envolvidas em cada uma dessas situações, representando-nos, diante dos outros de forma diferente em cada um desses contextos. Em certo sentido, somos posicionados - e também posicionamos a nós mesmos - de acordo com os "campos sociais" nos quais estamos atuando. (SILVA; HALL; WOODWARD, 2000, p. 30).

No que diz respeito ao trabalho doméstico, as mulheres referiram:

Eu gosto de ser uma dona de casa. Ter minha qualidade, né? Cuido de casa, cuido de filho, cuido de marido, cuido de roupa, cuido de tudo. (E. 4).

Eu gosto de ficar cuidando do meu lar, né? Eu num gosto de tá pelo mundo. Gosto sempre de tá cuidando dos meu fio. Quando meus fio nasceu, me dediquei só a eles porque eu tive muito medo de perder meus fio pra violência. (E. 11).

A despeito de diversos papéis sociais desempenhados pelas entrevistadas, políticos comunitários e enquanto trabalhadoras, para a maioria delas, com quase unanimidade, foram considerados os mais importantes, aqueles que as relacionavam com as tarefas domésticas. Castells (2002, p. 23) afirma que, em determinados momentos da vida, algumas autodefinições se confundem com determinados papéis desempenhados, como por exemplo, o momento em que ser pai é a mais importante autodefinição para um indivíduo. Paim (1995) observou que nas camadas populares a maternidade é considerada a experiência que garante o "ser mulher" em sua realização como sujeito desse universo simbólico, determinando sua função, status e posição social.

Parte dos relatos sobre o próprio corpo, algumas mulheres expressaram satisfação e outras insatisfação, como retratado abaixo:

0 que gosto é a barriga (está grávida). Não gosto dos peitos, porque tá cheio de estrias. (E. 3).

Não gosto de nada [do corpo] e se fosse pra mudar, tudo. Levantava peito, tirava barriga. (E. 4).

Meu corpo... Eu já gostei muito, porém tive filhos agora... Deformou um pouco, mas eu gosto muito do meu cabelo. Não, mudaria assim mesmo. (E. 10)

Quanto às referências autoidentitárias voltadas para o próprio corpo, pode-se observar que as percepções apontadas, guardam semelhanças com as explicações anunciadas por alguns autores. A este respeito, para Mauss (2003, p. 404-405), existem hábitos corporais que variam de acordo com a cultura e o período histórico. Assim, há uma "imitação prestigiosa" onde "a criança, como o adulto, imita atos bem-sucedidos que ela viu ser efetuados por pessoas nas quais confia e que têm autoridade sobre ela".

Goldenberg (2010) afirma que no Brasil existe um modelo de corpo específico (jovem, magro, em boa forma, sexy), que segundo Bourdieu (2003) seria um corpo distintivo, definido como capital e os diversos tipos de capital são as influências que definem as probabilidades de ganho em um campo da sociedade. No entanto, esse corpo só é conquistado por meio de investimento financeiro, trabalho, sacrifício e tempo. 


\section{CONCLUSÃO}

Do estudo realizado, foram analisadas duas categorias: Representação Social de Comunidade e Elementos da Autoidentidade. Na primeira categoria foram elencados caracteres com conotação positiva: união, busca de algo comum, luta por melhoria local. Por outro lado, foram apresentados elementos que reproduzem cenários de violência social, barulho excessivo, falta de respeito, falta de estrutura e de conforto, descritos como causadores de sérios transtornos para os moradores da comunidade como um todo.

Quanto aos elementos autoidentitários, algumas mulheres mencionaram aspectos subjetivos do próprio corpo, atribuindo em alguns casos, intensa conotação negativa. A este respeito, o que se pode notar é a forte influência midiática da construção cultural do corpo, que, segundo a literatura especializada exige uma situação econômica, que está fora dos padrões das participantes, conforme o perfil sociodemográfico descrito anteriormente. No que diz respeito ao papel social desempenhado, as entrevistadas se reportaram, quase unanimemente, ao que majoritariamente executam: as atividades domésticas. Foram apontados outros papéis sociais, como estudantes, trabalhadoras e mães, papéis estes que, segundo Castells (2002), em determinados momentos, representam a autoidentidade dos sujeitos.

Como os dados revelaram essas mulheres destituídas de qualificação profissional, de emprego, de estrutura financeira, se apegam às tarefas domésticas, pelas quais elas são primordialmente responsáveis. A partir da combinação destes fenômenos, é construído um significado institucional que as leva a se autoidentificarem como domésticas, pelo menos, até 0 momento em que foram interpeladas.

Pode-se afirmar que os dados obtidos, tanto no que diz respeito aos Elementos de Autoidentidade, quanto às características positivas e negativas com que as participantes se referiram à sua comunidade, têm corroborado as conclusões dos estudos referidos no artigo. Avalia-se, também, a necessidade da reali- zação de mais estudos que busquem analisar a percepção de mulheres de diferentes regiões brasileiras acerca de sua comunidade e sobre os elementos de autoidentidade. Tal questão pode ser considerada relevante, na medida em que esses estudos podem contribuir para o desenho de políticas públicas mais eficientes e para a implementação de ações que visem proporcionar ou viabilizar um maior empoderamento das mulheres moradoras em conjuntos habitacionais populares.

\section{REFERÊNCIAS}

BAUMAN, Zygmunt. Modernidade líquida. Rio de Janeiro: Zahar, 2001.

\section{BERGER, Peter; LUCKMANN, Thomas. A construção}

social da realidade. Petrópolis: Vozes, 1976.

BOURDIEU, Pierre. Os usos sociais da ciência: por

uma sociologia clínica do campo científico. São

Paulo: UNESP, 2003.

BRANCALEONE, C. Comunidade, Sociedade e Sociabilidade: revisitando Ferdinand Tönnies. Revista de Ciências Sociais, Fortaleza, v.39, n.1, p.98-104, 2008.

BURKE, Peter. História e teoria social. São Paulo: UNESP, 2002.

CAMPOS, Regina Helena de Freitas. Psicologia

social comunitária: da solidariedade à autonomia. 19.ed. Petrópolis: Vozes, 2014.

CASTELLS, Manuel. Paraísos comunais: identidade e significado na sociedade em rede. In: 0 poder $\mathbf{d a}$ identidade. São Paulo: Paz e Terra, 2002.

GIDDENS, Anthony. Modernidade e identidade. Rio de Janeiro: Zahar, 2002. 
GOLDENBERG, M. O corpo como capital: gênero, casamento e envelhecimento na cultura brasileira. REDIGE Revista de Design, Inovação e Gestão Estratégica, v.1, n.1, p.200, 2010.

IBGE Instituto Brasileiro de Geografia e Estatística. Pesquisa Nacional por Amostras e Domicílios: síntese de indicadores. 2.ed. Rio de Janeiro: IBGE, 2015.

LEANDRO, J.B. Comunidade: uma reflexão a partir de Zygmunt Bauman. Kairós Revista Acadêmica da Prainha, v.5, n.1, p.156-162, jan-jun. 2008. MAUSS, Marcel. Sociologia e antropologia. São Paulo: Cosac Naify, 2003.

MOCELLIM, A.D. A comunidade: da sociologia clássica à sociologia contemporânea. Plural. Revista do Programa de Pós-Graduação em Sociologia da USP, São Paulo, v.17, n.2, p.105-125, 2011.
PAIM, Heloísa Helena Salvatti. Marcas no Corpo: gravidez e maternidade em grupos populares. In: DUARTE, L.F.D. (Org.). Doença, sofrimento, perturbação: perspectivas etnográficas. Rio de Janeiro: FIOCRUZ, 1998. p.210.

\section{PENA, Maria Valéria Junho. Mulheres e}

trabalhadoras: presença feminina na constituição do sistema fabril. Rio de Janeiro: Paz e Terra, 1981.

\section{ROCHA-COUTINHO, Maria Lúcia. Tecendo por trás dos panos. Rio de Janeiro: Rocco, 1994.}

\section{SÁ, Celso Pereira de. Representações sociais: 0} fenômeno, o conceito e a teoria geral. Rio de Janeiro: EDUERJ, 2015. p.183-208.

SILVA, Tomaz Tadeu; HALL, Stuart; WOODWARD, Kathryn. Identidade e diferença: a perspectiva dos estudos culturais. Petrópolis: Vozes, 2000.

TOLEDO, Cecília. Mulheres: o gênero nos une, a classe nos divide. 2.ed. São Paulo: Sundermann, 2008.

\begin{abstract}
1 Doutora em Psicossociologia de Comunidades e Ecologia Social pela Universidade Federal do Rio de Janeiro - UFRJ; Professora de Metodologia de Pesquisa do Departamento de Psicologia da Universidade Federal de Sergipe - UFS; Líder do grupo de Pesquisa Desenvolvimento, Saúde e Políticas Coletivas a partir do qual coordena pesquisa em Comunidade de baixa renda, junto a mães de bebês prematuros e desenvolvimento cognitivo, motor e comportamental de bebês nascidos prematuramente. E-mail: elzafrancisca@gmail.com

2 Doutor em ordenamento territorial e meio ambiente pela Universidade de Zaragoza; Professor do Departamento de Geografia da Universidade Federal de Sergipe - UFS; membro de grupos de pesquisa e extensão dentro e fora da Universidade Federal de Sergipe - UFS; Trabalha na área da Geografia da população e análise de indicadores sociodemográficos para o planejamento e gestão pública. E-mail: nmeneses@bol.com.br

3 Doutoranda e mestre em Psicologia Social pela Universidade do Estado do Rio de Janeiro - UERJ; Realiza trabalho clinico voltado para orientação vocacional. E-mail: stella.rkappler@gmail.com

4 Graduanda do curso de Ciência Sociais da Universidade Federal de Sergipe - UFS; Bolsista do Programa de Iniciação à Extensão PROEX/PIBIX/UFS, PIBIC/VOLUNTÁRIO (IC) e membro do grupo de pesquisa Saúde, Desenvolvimento e Políticas Coletivas. E-mail: rhi@hotmail.com.br

5 Graduada em Psicologia pela Universidade Federal de Sergipe - UFS; Membro do grupo de pesquisa Desenvolvimento, Saúde e Políticas Coletivas. E-mail: isinha204@gmail.com
\end{abstract}


